\title{
TEKNIK PEMERIKSAAN BARIUM ENEMA PADA PASIEN ANAK DENGAN DENGAN KLINIS MORBUS HIRSCHPRUNG
}

\author{
Sri Hartati ${ }^{1}$, Aldistira Yusda ${ }^{2}$ \\ ${ }^{1,2}$ D3 Radiologi, ATRO Nusantara Jakarta \\ Corresponding author: Sri Hartati \\ Email: hartati2311@yahoo.com
}

\begin{abstract}
Background: Based on differences in theory with the field that focuses on 4 different factors, namely the use of Iodine contrast material which should be BaSO4 (Bontrager, 2012), the use of Nelaton Catheter which should be a Polycatheter or Barium set (Bontrager, 2012) and (Ballinger, 2012), the addition of Prone position on plain abdominal photo examination should only be in the Supine position, using the Oblique R / L position (Optional) which should only be plain AP photo, AP contrast, Lateral contrast, and AP Post evacuation (Bontrager, 2012)

Methods: Qualitative descriptive, which is carried out by means of observation, interviews, literature review and documentation (photo taking), research This was carried out for 6 months with a total population of ten patients and a sample of three patients with details of one primary sample and two secondary samples.

Results: Image analysis, and comparison of Barium Enema Pediatric examination techniques in the territory with the field obtained from interviews with three radiographers and three radiologists.

Conclusions : The pediatric Barium enema examination technique is performed under fluoroscopy control with the ratio of contrast material to the liquid is 1: 4 and 1: 2 for Hirschprung Suspect and 2: 3 for clinical Morbus Hirschprung on Colostomy as well as AP and PA projection shooting techniques for preliminary photos, AP supine with contrast, lateral to contrast, and photographs 24 hours after examination (post evacuation).
\end{abstract}

Keyword : Enema, Pediatric, Hirschprung

\section{Pendahuluan}

Pemeriksaan radiologi dengan sinar-x sangat berperan dalam mendukung atau dalam menegakkan diagnosa suatu penyakit, baik itu pemeriksaan dengan kontras maupun tanpa kontras. Pemeriksaan Barium Enema adalah pemeriksaan secara radiologi sistim pencernaan dengan menggunakan bahan kontas ke dalam Colon secara Retrograde. (Bontrager, 2012) Proyeksi yang biasa digunakan dalam pemeriksaan Barium Enema adalah proyeksi AP, Lateral, Oblique, AP Axial, PA Axial, LLD, dan Axial Chassard Lapine Methode. (Ballinger, 2012)

Seiring berjalannya waktu, pemeriksaan radiologi barium enema juga mengalami perkembangan yang pesat khususnya dalam teknik pemeriksaan Barium Enema Pediatric, seperti nama pemeriksaannya, umumnya pemeriksaan Barium
Enema menggunakan BaSO4 (Barium Sulfat) untuk menampilkan mukosa Colon yang akan diperiksa. (Bontrager, 2012)

Pada prosedure pemeriksaan barium enema pada anak, banyak hal yang menjadi perhatian, hal ini antara lain disebabkan oleh kondisi pasien anak yang belum bisa kooperatif, pergerakan dari pasien, kesulitan berkomunikasi, penggunaan media kontras dikarenakan mengingat sensitifnya organ pencernaan anak, serta faktor lainnya, sehingga pemeriksaan Barium Enema pada anak memerlukan penanganan khusus.

Salah satu klinis yang sering muncul pada pemeriksaan Barium Enema Pediatric adalah Morbus Hirschprung, yaitu suatu kelainan yang disebabkan oleh kegagalan perkembangan dari Fleksus Submukosa Meissner dan Fleksus Mensentrik Aurbach. Bagian Colon ini tidak dapat mengembang sehingga tetap sempit dan terjadinya 
Defekasi. Akibat gangguan Defekasi ini Colon bagian Proksimal yang normal akan melebar oleh feses yang menumpuk membentuk pembesaran Colon. Diketahui bahwa Morbus Hirschprung terdiri atas 4 jenis yaitu Morbus Hirschprung Aganglionik pendek, Morbus Hirschprung Aganglionik panjang, Morbus Hirschprung Aganglionik total dan Morbus Hirschprung Universal. (Robus and Kumar, 2011)

\section{Metode}

Penelitian ini bersifat Deskriptif Kualitatif untuk mengetahui bagaimana teknik pemeriksaan Barium Enema Pediatric dilakukan pada pasien anak, yang bertujuan untuk mengetahui atau memperlihatkan struktur dari Anatomi dan Fisiologi Colon yang diperiksa dengan cara mendapatkan gambaran radiograf yang optimal, yang di hasilkan dari teknik pemeriksaan Barium Enema Pediatric dengan penggunaan bahan kontras Iodine ditambah dengan penggunaan Nelaton Catheter. Penelitian ini dilakukan November 2018 - April 2019. Dengan Sample sebanyak 3 pasien pedriatric.

\section{Hasil dan Pembahasan}

1. Paparan Kasus dan Riwayat Pasien

Dari bulan November 2018 sampai April 2019, diamati 3 objek penelitian. Adapun rentang umur adalah $1-4$ tahun. Dengan data sample pada table berikut

Table 1. Karakteristik Sample

\begin{tabular}{|c|c|c|c|c|}
\hline Sampel & Nama & $\begin{array}{c}\text { Umur } \\
\text { (th) }\end{array}$ & $\begin{array}{c}\text { Jenis } \\
\text { Kelamin }\end{array}$ & Klinis \\
\hline S1 & An. A & 4 & L & MH \\
\hline S2 & An. B & 1 & P & MH \\
\hline S3 & An. C & 1 & L & $\begin{array}{c}\text { MH } \\
\text { Colostomy }\end{array}$ \\
\hline
\end{tabular}

2. Prosedur Pemeriksaan barium enema pediatric dengan dengan klinis morbus hirschprung.

Teknik pemeriksaan Barium Enema Pediatric pada klinis Hirschprung hanya dilakukan proyeksi foto pendahuluan AP dan PA, AP kontras, Lateral kontras, foto Post Evakuasi (24 jam). Langkahlangkah pemeriksaan Barium Enema Pediatric sebagai berikut :

\section{1) Persiapan Pasien}

Premedikasi seharusnya dapat di berikan kepada pasien yang tidak kooperatif, seperti pemberian obat bius atau Anastesi, tetapi di lapangan Premedikasi jarang di lakukan untuk menghindari terjadinya komplikasi lain terhadap pasien sehingga proses Premedikasi tidak di berikan, di lain hal proses fiksasi lebih di utamakan untuk pasien terkhusus pasien anak. Persiapan pasien lainnya yaitu 24 jam sebelum pemeriksaan Anus tidak boleh di colok-colok di khawatirkan adanya udara yang masuk dan terjadinya manipulasi gambaran, karena ciri Hirschprung adalah tidak adanya udara di dalam Colon.

\section{2) Persiapan Alat dan Bahan}

Catheter yang digunakan adalah Polycather (Bontrager, 2012) dan ( Ballinger,2012) sedangkan yang digunakan di lapangan adalah jenis Catheter Nelaton, penggunaan Nelaton lebih aman dan hasilnya tidak akan mengganggu gambaran, penggunaan Polycatheter bisa saja digunakan tanpa menggunakan system balonning tetapi untuk menghindari kesalahan prosedur pemeriksaan yang mengakibatkan mengembangnya balon sehingga terjadinya penekanan pada dinding mukosa colon dan mengakibatkan Superposisi balon dengan bagian organ yang akan diperiksa pada saat melakukan Eksposi.

\section{3) Penggunaan Bahan Kontras}

Penggunaan bahan kontras berdasarkan teori adalah BaSO4 dengan konsentrasi kontras 1:8 (Bontrager,2012), berdasarkan hasil observasi, menggunakan bahan kontras Iodine karena sifat dari kontras Iodine mudah di serap oleh tubuh, mengingat sensitifnya Colon anak maka kontras Iodine cocok di gunakan untuk pemeriksaan Barium Enema Pediatric dibandingkan BaS04 yang bersifat cepat mengkristal sehingga menyulitkan pembuangan kontras setelah pemeriksaan di lakukan. Perbandingan kontras yang digunakan tergantung tergantung dai klinis dan Anatomi Colon masing-masing pasien.

4) foto pendahuluan,

Dibuat 2 foto pendahuluan yaitu 1) proyeksi AP dengan Central Ray tegak lurus Vertical. Pasien Posisi Supine dan 2). PA dengan Central Ray Horizontal, dengan posisi pasien prone tujuannya 
untuk melihat transisi udara daerah Colon. Tujuan umum dibuat foto pendahuluan adalah untuk melihat gambaran Abdomen secara umum, melihat persiapan yang dilakukan oleh pasien serta kemungkinan adanya kontra indikasi dan menentukan faktor Eksposi pada proyeksi selanjutnya.
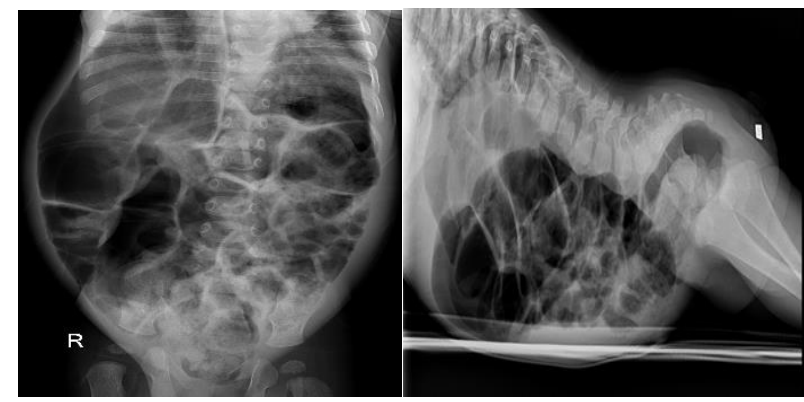

Gambar 1 Hasil radiografi Foto Pendahuluan

\section{2). Pemasukan Bahan Kontras}

Berdasarkan hasil pengamatan, kontras media yang disiapkan untuk pemeriksaan Barium Enema Pediatric memiliki berbagai variasi konsentrasi kontras (jumlah kontras Iodine di banding dengan jumlah cairan terlarut), variasi tersebut dapat memiliki perbandingan 1:2 atau 1:4 untuk klinis Suspect Morbus Hirschprung dan 2:3 untuk klinis Morbus Hirschprung on Colostomy dengan tujuan evaluasi hasil pembedahan Colon setelah dilakukan pemeriksaan Loopografi. Variasi kontras tersebut dilakukan atas dasar daya tampung Colon setiap anak berbeda ditambah lagi dengan berat badan yang tidak normal dari tubuh anak yang akan diperiksa, berat badan anak yang mempunyai kelainan Hirschprung diatas berat badan anak seusianya dikarenakan perut yang mengalami pembesaran, tetapi untuk persiapan kontras Morbus Hirschprung on Colostomy digunakan konsentrasi kontras dan cairan terlarut sama banyak untuk lebih memperjelas gambaran evaluasi Colon yang telah dilakukan pembedahan.

Kontras media yang telah disiapkan dicampur dengan Nacl di dalam bengkok Kemudian diaduk dengan merata, lalu isi Catheter Tip 50 cc dengan kontras media dan $\mathrm{NaCl}$ yang sudah dicampur sebelumnya. Hubungkan Nelaton no. 8 atu Nelaton no. 12 dengan Catheter Tip $50 \mathrm{cc}$ tergantung keadaan pasien, berikan karet putih supaya Nelaton tidak mudah lepas dari Catheter Tip. Lapisi Nelaton dengan Vaseline kemudian masukan ke dalam Anus pasien kurang lebih $2 \mathrm{~cm}$. Kedua Musculus Gluteus Maximus pasien dirapatkan dan diberikan plester agar Nelaton tidak mudah lepas. Kontras media dimasukkan melalui
Nelaton secara bertahap ke Anus pasien sebanyak 5 cc pada posisi AP untuk mengevaluasi jalannya kontras.

Kemudian pasien langsung diposisikan True Lateral dengan kedua tangan dan lutut dipegangi oleh keluarga pasien dan jalannya kontras media dikontrol dengan Flouroskopi. Kontras media perlahan mulai mengisi daerah Distal Colon. Jika belum terlihat kelainan Anatomi pada Colon, maka akan dilakukan penambahan Volume kontras media sesuai dengan kebutuhan pemeriksaan

\section{5) Proyeksi Lateral Kontras}

Tujuan dari proyeksi Lateral yaitu untuk melihat penyempitan pada daerah Rectosigmoid, sebab pada klinis Hirschprung terlihat kelainan anatomi pada daerah tersebut. Pasien diposisikan True Lateral dengan salah satu tubuh menempel pada meja pemeriksaan. Objek yang akan diperiksa diletakkan pada pertengahan meja pemeriksaan, kedua tangan diletakkan di atas kepala dan dua kaki di tekuk lalu dipegangi oleh keluarga pasien, untuk menghindari pergerakan pasien. Centray Ray tegak lurus Vertical dengan meja pemeriksaan. Menggunakan luas lapangan kolimasi sesuai dengan objek yang diperiksa yaitu batas atas Processus Xyphoideus dan batas bawah Symphsis Pubis. Kontras media dimasukkan kembali $15 \mathrm{cc}$.

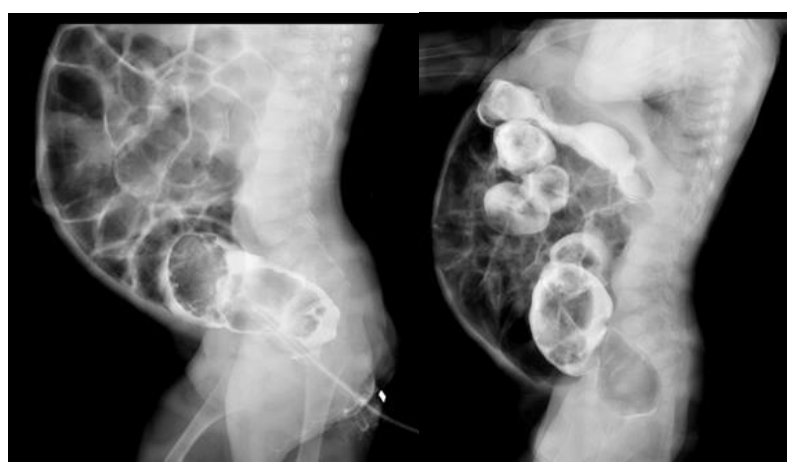

Gambar 2. Proyeksi lateral Post pemasukan Bahan Kontras

\section{4) Proyeksi AP kontras}

Kontras media dimasukkan melalui Anus menggunakan Nelaton secara bertahap sebesar 30 cc sampai terlihat adanya perbedaan struktur anatomi Colon dari bagian Distal hingga Proksimal. Tujuan dari pengambilan foto proyeksi AP yaitu untuk melihat bentuk dan struktur keseluruhan Colon. Struktur gambaran memperlihatkan gambaran Colon proyeksi AP 
dengan kontras yang mengisi bagian Rectum, Sigmoid, Colon Descenden, Flexura Lienalis, Colon Trasversum, Flexura Hepatica dan Colon Aescenden. Terdapat Caliber Rectum hingga Sigmoid Distal pada level kira-kira pada Corpus Collumna Vertebrae Lumbal ke-5 lebih kecil dibandingkan Sigmoid Proximal, dan Dilatasi Colon di bagian Proximal pada zona transisi di level Sigmoid Distal pada Corpus Collumna Vertebrae Lumbal ke-3.

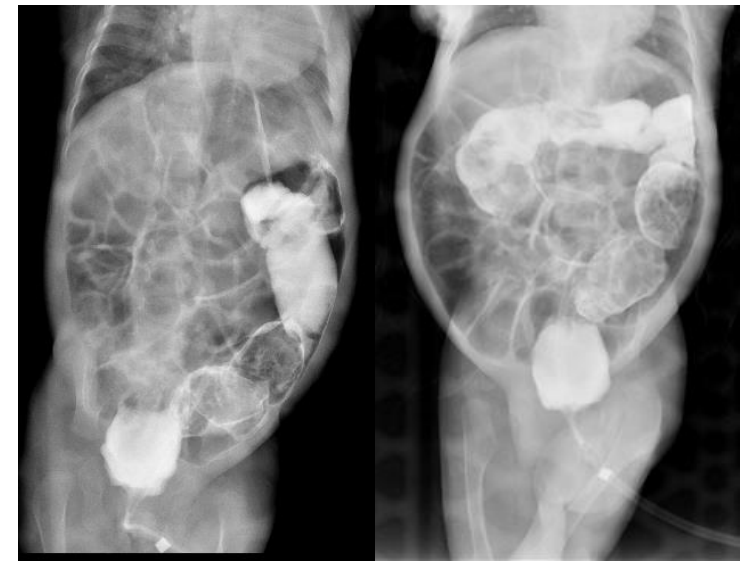

Gambar 3. Proyeksi AP Post pemasukan bahan kontras

\section{6) Foto Post Evakuasi (24 jam)}

Pengambilan foto yang dilakukan pada pemeriksaan Barium Enema Pediatric yang terakhir adalah pengambilan foto 24 jam dengan proyeksi AP Supine. Tujuan pengambilan foto 24 jam yaitu untuk memperlihatkan Retensi kontras media Iodine serta pengeluarannya sebagai informasi tambahan pada klinis yang terjadi.

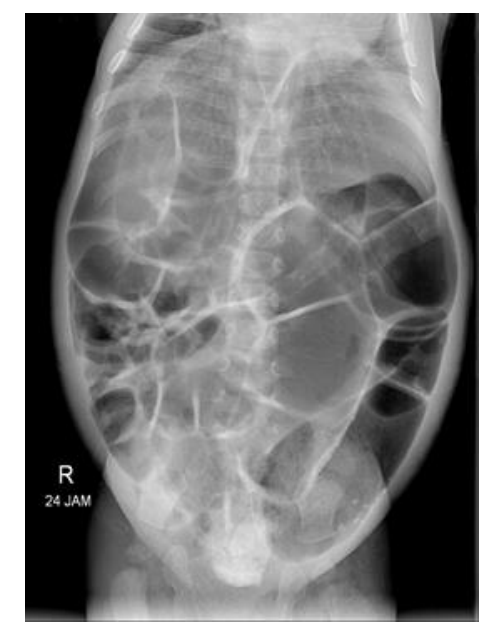

Gambar 4 : Post Evakuasi 24 Jam

\section{Simpulan}

Teknik Pemeriksaaan Barium enema pediatric dilakukan dengan beberapa persiapan khusus terkait persiapan bagi pasien, persiapan alat, bahan kontras serta serta teknik pemeriksaan. Penggunnaan Alat bantu Catheter Tip, serta penggunaan bakan kontras yang tepat, akan mendukung dihasilkannya gambaran radiologi yang optimal. Teknik pemeriksaan Barium Enema pediatric harus dilakukan dibawah control Fluoroscopy dengan perbandingan bahan kontras dengan cairan terlarut yang di gunakan adalah 1:4 dan 1:2 untuk Suspect Hirschprung dan 2:3 untuk klinis Morbus Hirschprung on Colostomy. Teknik pemotretan proyeksi $A P$ dan $P A$ untuk foto pendahuluan, $A P$ supine dengan kontras, Lateral $\mathrm{R} / \mathrm{L}$ dengan kontras, dan foto 24 jam setelah pemeriksaan dilakukan ( Post Evakuasi ).

\section{Daftar Pustaka}

Ahmad, Ramli. 2013. Kamus Kedokteran. Cetakan ke-13 , Djambatan : Jakarta ; 2013

Ballinger , Philip W , 2012. Merill's Atlas of Radiographic Positioning and Radiologic Prosedur. Volume Two.Eight Edition. Mosby Company, St.Louis.

Bontrager , Kenneth L , 2012 . Text Book Of Radiographic Positioning and Related Anatomy. Mosby A Harcourt Science Company St.Louis London Philadelphia Sidey Toronto.

Brunner and Suddarth . 2011 , Buku ajar keperawatan medical bedah. Eight Edition. Volume 2 . Jakarta EGC ; 2011

Bambang Setyo \& Idrus Alwi. 2015 . Ilmu Penyakit Dalam. Jilid II. Five Edition. Jakarta : 2015 . http: //www.pendidikankesehatan.co.ccc//2011/03/askepilmupenyakitdalam.html

Betz , Cecily L, Sowden, Linda A. 2012. Buku Saku Keperawatan Pediatric . Five Edition , Jakarta : EGC

Moore, Keith L Agur, Anne M.R , 2012. Anatomi Klinis Dasar. Laksman, H. eds. Jakarta : Hipokrates.

Pearce,Evelyn C,2012. Anatomi dan Fisiologi Paramedis. Jakarta Gramedia.

Rasad, Sjahriar, Radiologi Diagnostik Edisi Kedua , 2012, FKUI. JAKARTA. Seeram 
JURNAL RADIOGRAFER INDONESIA p-ISSN 2620-9950

Euclid. Second Edition. W.B Saunders Company.

Stewart Carlyle Bushong, 2013, Radiologic Science for Technologist, Physics, Biology and Protection 